\title{
Assessment of Stress on Serum Estradiol and Cortisol Levels in Female Subordinate Naked Mole Rats Following Isolation from Natal Colony
}

\author{
Amos Onyansi Makori' ${ }^{1}$ Albert Wafula Nyongesa ${ }^{2}$, Hesbon Odongo ${ }^{3}$, Rael Jepkogei Masai ${ }^{1}$ \\ ${ }^{1}$ Department of Biological Sciences, Kisii University, Kisii, Kenya \\ ${ }^{2}$ Department of Veterinary Anatomy and Physiology, University of Nairobi, Nairobi, Kenya \\ ${ }^{3}$ School of Biological Sciences, University of Nairobi, Nairobi, Kenya \\ Email: msmakori@gmail.com, jjepkogei@gmail.com, albertnyongesa@gmail.com, hesodongo@gmail.com
}

How to cite this paper: Makori, A.O., Nyongesa, A.W., Odongo, H. and Masai, R.J. (2020) Assessment of Stress on Serum Estradiol and Cortisol Levels in Female Subordinate Naked Mole Rats Following Isolation from Natal Colony. Journal of Biosciences and Medicines, 8, 9-17.

https://doi.org/10.4236/jbm.2020.83002

Received: January 20, 2020

Accepted: February 29, 2020

Published: March 3, 2020

Copyright $\odot 2020$ by author(s) and Scientific Research Publishing Inc. This work is licensed under the Creative Commons Attribution International License (CC BY 4.0).

http://creativecommons.org/licenses/by/4.0/

cc) (i) Open Access

\begin{abstract}
This study investigated the effects of isolation of subordinate naked mole rats from natal colonies on their reproductive success. Naked mole rat is one of the known mammals that exhibit eusociality. It has been noted that naked mole rats have their reproduction restricted to one queen and less than three males; the rest of the animals within the colony remain sterile. The study aimed at establishing whether the reproductive suppression in subordinate naked mole rats is the outcome of social stress exerted by breeding female in the colony or other unknown environmental factors within the colony set-up. Experimental period was 20 weeks and it involved two stages, acclimatization and isolation. Before acclimation, 2 female subordinate naked mole rats were sacrificed. Blood samples were collected and appropriately preserved for later analysis. On the $2^{\text {nd }}, 4^{\text {th }}$ and $6^{\text {th }}$ weeks of acclimatization, 2 female mole rats were sacrificed at each stage and blood samples were harvested for analysis. On week 7, eighteen subordinate females were isolated and randomly assigned into two groups of 9 animals each in two separate cages for 14 weeks. One week 8, 2 subordinate females from each group were randomly selected, sacrificed and blood samples collected for analysis. The same procedure was repeated on week 12 and 20 of study. Hormonal analysis was done using ELISA technique. The Statistical analysis done using student $\mathrm{t}$-test at $95 \%$ confidence level and significance level was set at $\mathrm{P}<0.05$. Results showed increase in cortisol levels only in singly isolated females which were the greatest on week 8 (from $35.5 \mathrm{ng} / \mathrm{ml}$ to $123.4 \mathrm{ng} / \mathrm{ml}$ ). Mean estradiol in singly isolated females was $18 \pm 2.52 \mathrm{pg} / \mathrm{ml}$ while females paired with males had $19.0 \pm 3.0$ $\mathrm{pg} / \mathrm{ml}$ hence no significant difference (paired $\mathrm{t}=-1.73, \mathrm{P}=0.23$ ). Conclu-
\end{abstract}


sively, the observed reproductive suppression among subordinate naked mole rats in natal colonies is probably due to presence of queen or other reproductive aspects that may not be directly related to stress.

\section{Keywords}

Isolation, Subordinate Naked Mole Rat, Reproductive Success, Stress, Estradiol

\section{Introduction}

Naked mole rats (Heterocephalus glaber) are found in many parts of Makueni and Kitui Counties, in Kenya. Their reproduction is restricted to one queen and less than three males; the rest of the animals within the colony remain sterile. The proximate mechanisms of reproductive skew observed among the cooperative breeders have been studied. For instance, in Marmoset monkeys, a combination of behavioural and pheromonal signals from the dominant female brings about insufficient secretions of gonadotrophic hormones in other females [1]. Similar studies on Meerkats showed that physical aggression by dominant breeder towards the subordinate females was responsible for reproductive suppression [2]. The factors underlying reproductive inhibition among subordinate female naked mole rats in a natal colony remain obscure. Whether or not this inhibition results from social stress exerted by the breeding female, preference by breeding males to the queen over subordinate females or due to other ecological factors remain to be elucidated. The present study, therefore, interfered with the natal colony set up in order to explore the possibility that reproductive suppression on the female subordinate naked mole rats could be a form of stressor that impairs cyclicity, reproductive hormone synthesis and secretion and, therefore, reproductive success. Since the study considered isolation to be a form of stress, eusociality of the naked mole rats made them ideal animal model for the present study. The findings of this study would provide the basis for studying variations in reproductive hormones which could be applicable to human beings when exposed to stress and how these contribute to trade-offs with reproduction.

\section{Materials and Methods}

\subsection{Animal Capture, Sexing and Housing}

Forty naked mole rats were captured by simple random sampling technique from different natal colonies through live traps method. The method adopted previous description for trapping terrestrial animals [3]. Briefly, Irish potatoes were introduced closer to the entrance of the tunnels of the natal colony to act as bait. Then the animals were captured before they could run back into the inner side of the tunnels. Sexing was done before introduction of the animals into the artificial colony. Each animal was examined around the genital area, between the 
two orifices, for the presence of a horizontal red line, a characteristic anatomical feature for females. The animals were marked with a tattoo ink for easy identification since they are homomorphic in appearance. Captive colony was made in artificial burrow system consisting of small cubical Plexiglas chambers $(20 \mathrm{~cm} \times$ $20 \mathrm{~cm} \times 20 \mathrm{~cm}$ ) linked by transparent glass tubing of $3 \mathrm{~m}$ tunnel system in a dimly lit room maintained at approximately $26^{\circ} \mathrm{C}$ room temperature with humidity of approximately $60 \%$. The animal house was cleaned daily and food supplied at the opening of the cubical boxes daily. Beddings for the animals were dry treated sawdust that was preferred due to its absorbency nature [4].

\subsection{Experimental Design}

This comprised of three groups: two for experimental groups. Group one comprising of nine singly isolated females (SIF) while group two consisted of nine female paired with three males (FIP) and nine non-isolated females (NIF) that remained together with two males in the parent colony were the controls. The experiment was carried out in two phases: acclimatization and isolation.

\subsubsection{Acclimatization}

Before acclimatization, 2 female subordinate naked mole rats were sacrificed. Blood samples were collected and appropriately preserved for later analysis. On the $2^{\text {nd }}, 4^{\text {th }}$ and $6^{\text {th }}$ weeks of acclimatization, 2 female mole rats were sacrificed at each stage and blood samples, were harvested for analysis. Acclimatization covered the period between day 1 and week 6 of study while all animals were still in parent colony.

\subsubsection{Isolation from Parent Colony}

Isolation was done on week 7 of experimental period. Eighteen subordinate females were isolated and randomly assigned into two groups of 9 animals each in two separate cages for 14 weeks. One week 8, 2 subordinate females from each group were randomly selected, sacrificed and blood samples collected for analysis. The same procedure was repeated on week 12 and 20 of study.

\subsection{Animal Euthanasia}

To ensure humane death, isoflurane was administered through inhalation using soaked cotton wool for $30 \mathrm{~min}$ in fuming chamber followed by decapitation.

\subsection{Blood Sampling}

Blood sample was collected using a $23-\mathrm{G}$ needle directly from the apex of left ventricle after thoracotomy following anaesthesia with isoflurane (Sundent Pharmaceutical Co., Ltd., Shanghai, China) in a sealed chamber. About $500 \mu \mathrm{l}$ of blood sample was collected into red-topped vacuitainers followed by centrifugation at $1000 \mathrm{rpm}$ and serum decanted into clearly labelled ependorff tubes (by animal identity and date of collection) and subsequently frozen at $-20^{\circ} \mathrm{C}$ until hormone analysis. 


\subsection{Hormone Analysis}

\subsubsection{Cortisol Assay}

Serum cortisol was assayed using ELISA technique according to the manufacturer's protocol. The technique applies the principle of competition for limited binding sites on the specific antibody by both the hormone in sample and enzyme-conjugated hormone in the coated plates. First, the serum samples were thawed and homogenized by centrifugation. Twenty five microliters of the standards, sample and quality controls were first pipetted into the microtitre plate wells. Then $200 \mu \mathrm{l}$ of Enzyme Antigen Conjugate was added and mixture incubated for $60 \mathrm{~min}$ at $25^{\circ} \mathrm{C}$ followed by aspiration of contents and addition of 400 $\mu \mathrm{l}$ of Wash solution. The washing procedure was repeated twice with a soak time of $30 \mathrm{sec}$ before aspiration of the wash solution. Then $100 \mu \mathrm{l}$ of the substrate solution was added and the mixture incubated for $15 \mathrm{~min}$ at $25^{\circ} \mathrm{C}$. Then $100 \mu \mathrm{l}$ of the Stop solution was added followed by determination of absorbance at wavelength of $450 \mathrm{~nm}$ within $30 \mathrm{~min}$. The assay reagents (quality controls, standards, blanks and samples) were done in duplicate. The optical density of specimen was measured using HumaReader HS equipped with $450 \mathrm{~nm}$ filters (Gessellschaft für Biochem und Diagnostica, $\mathrm{mbH}$, Germany).The assay sensitivity for cortisol was $1.1-1.5 \mathrm{ng} / \mathrm{ml}$. The intra-assay coefficient of variation was less than $15 \%$ while the inter assay coefficient of variation was less than $10 \%$.

\subsubsection{Estradiol Assay}

Assay was also done by ELISA as per the protocol. After thawing reagents and specimen, twenty five microliters of the calibrators, specimen and controls were first pipetted into the micro plate wells. Then $100 \mu \mathrm{l}$ of the Enzyme Antigen Conjugate was added and vortex mixed. The mixture was incubated for $60 \mathrm{~min}$ at $25^{\circ} \mathrm{C}$. Then all the contents were aspirated followed by addition of $400 \mu \mathrm{l}$ of Wash solution. Washing procedure was repeated twice with a soak time of $30 \mathrm{sec}$ before aspiration of the wash solution. Then $100 \mu \mathrm{l}$ of the substrate solution was added and the mixture incubated for $15 \mathrm{~min}$ at $25^{\circ} \mathrm{C}$. Then $50 \mu \mathrm{l}$ of Stop solution was added and mixed carefully followed by measurement of absorbance at 450 $\mathrm{nm}$ within $10 \mathrm{~min}$. The assay procedure was also done in duplicate. The optical density of specimen was measured using Huma Reader HS equipped with 450 $\mathrm{nm}$ filters. The assay sensitivity for estradiol was $13 \mathrm{pg} / \mathrm{ml}$. The intra-assay coefficient of variation was less than $15 \%$ while the inter assay coefficient of variation was less than $10 \%$.

\subsection{Statistical Analysis}

The quantitative data on hormonal levels were analyzed with IBM SPSS statistics version 20 yielding both descriptive and inferential statistical data. Data on hormonal levels are presented as mean \pm S.E.M. The statistical differences between groups were determined by paired t-test. All the tests were two-tailed $\mathrm{t}$-tests and the significance level was set at $\mathrm{P}<0.05$. 


\subsection{Quality Control}

To ensure validity on the data for hormone assay, the controls were assayed with a calibration curve and the quality control samples were run in triplicate alongside samples and standards and the mean values obtained were within the acceptable ranges. The pipetting was done quickly and with precision of the aliquots to avoid assay drift that could influence reliability of the results. The intra assay coefficients of variation were $3.10 \%$ for cortisol and $11.89 \%$ for estradiol.

\section{Results}

\subsection{Effects of Colony Re-Organization on Serum Cortisol}

The mean serum cortisol levels during acclimation decreased significantly from 117.7 to $35.5 \mathrm{ng} / \mathrm{ml}$ from day 1 to week $6(\mathrm{t}=3.49, \mathrm{P}=0.04)$. After acclimation, there was $5.5 \%$ increase in the serum cortisol between week 8 and 1 week 12 in SIF. The increase in mean cortisol levels in SIF was greatest at the time of isolation from $35.5 \mathrm{ng} / \mathrm{ml}$ to $123.4 \mathrm{ng} / \mathrm{ml}$ compared to levels between week 8 and week 12, whereby the hormone increased from 123.4 to $130.2 \mathrm{ng} / \mathrm{ml}$. However, there was $7.1 \%$ percentage decrease in serum cortisol in NIF. Similarly, in FIP, there was $9.9 \%$ decrease in serum cortisol levels between week 8 and 12. By week 20 mean serum cortisol levels in SIF had decreased significantly from 130.2 to $88.2 \mathrm{ng} / \mathrm{ml}(\mathrm{t}=8.74, \mathrm{P}=0.01)$, NIF from 108.1 to $90.4 \mathrm{ng} / \mathrm{ml}(\mathrm{t}=19.48, \mathrm{P}=$ $0.01)$ and FIP from 100.2 to $87.4 \mathrm{ng} / \mathrm{ml}(\mathrm{t}=23.92, \mathrm{P}=0.002)$. However, there was no significant difference in cortisol levels between the SIF and NIF $(t=1.54$, $\mathrm{P}=0.263$ ) as well as FIP and NIF during this period (Figure 1).

\subsection{Effects of Colony Re-Organization on Serum Estradiol in Females}

The serum estradiol levels increased significantly during acclimation with a mean of $14.5 \pm 0.96 \mathrm{pg} / \mathrm{ml}(\mathrm{t}=15.15, \mathrm{P}=0.001)$. The SIF had $6.3 \%$ decrease in serum estradiol level between week 8 and 12 compared to NIF with $14.4 \%$ increase while FIP had $1.9 \%$ increase in serum estradiol levels. By week 20, the SIF had a significant increase in Estradiol levels with mean values of $18 \pm 2.52 \mathrm{pg} / \mathrm{ml}$ $(\mathrm{t}=7.15, \mathrm{P}=0.02)$ compared to NIF with mean of $15 \pm 0.58 \mathrm{pg} / \mathrm{ml}$. The mean serum estradiol levels in FIP also increased significantly from 16.1 to $25.0 \mathrm{pg} / \mathrm{ml}$ $(\mathrm{t}=6.33, \mathrm{P}=0.02)$. The mean estradiol levels in FIP were $19.0 \pm 3.0 \mathrm{pg} / \mathrm{ml}$. There was no significant difference in mean estradiol levels between the SIF and FIP (paired $t=-1.73, \mathrm{P}=0.23$ ) (Figure 2).

Results (Pearson correlation, significance level set at $\mathrm{P}<0.05$ ) showed no significant correlation between cortisol and estradiol levels during acclimation $(\mathrm{r}=$ $-0.755, \mathrm{P}=0.245)$. After isolation, there was significant negative correlation in isolated females $(\mathrm{r}=-0.999, \mathrm{P}=0.023)$ but insignificant correlation in females paired with males $(r=-0.677, P=0.526)$ and the non-isolated females. 


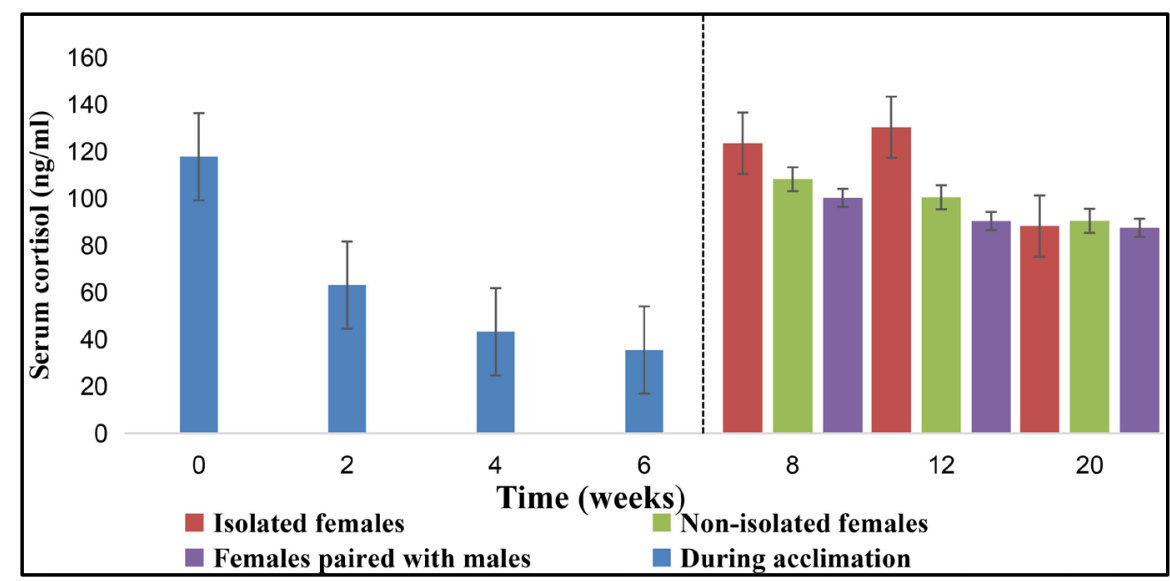

Figure 1. Pattern of mean serum cortisol measured over 20 weeks with the first 6 weeks showing hormone values during acclimation period while from week 8 to week 20 denotes period of re-grouping to isolated, non-isolated and pairing as shown in the key above. The dotted line denotes the time when isolation was done.

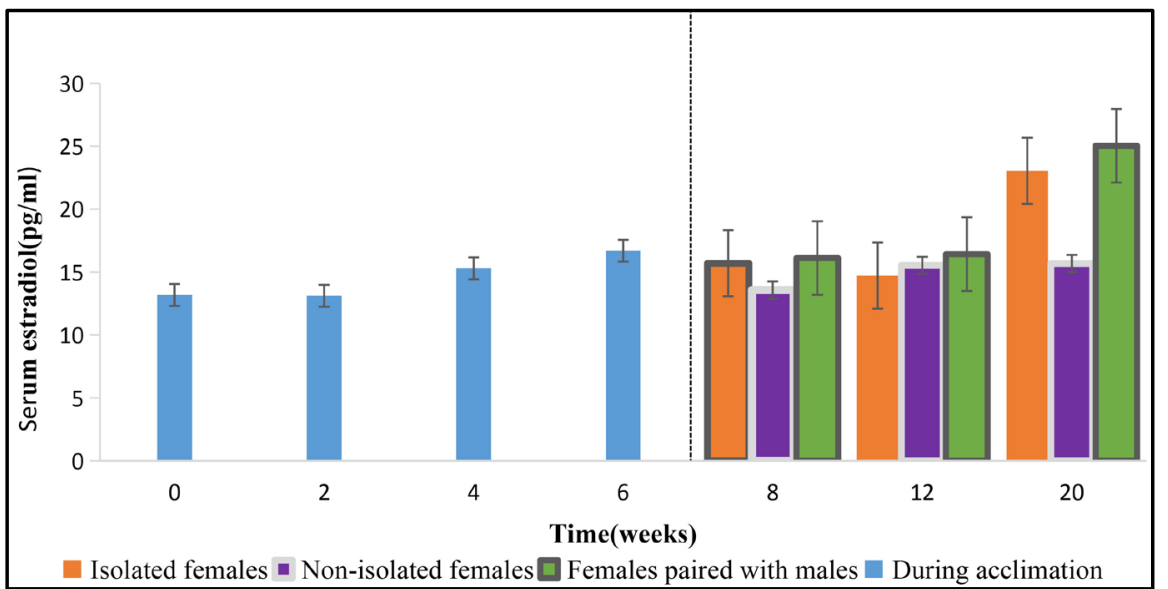

Figure 2. Mean serum estradiol levels of naked mole rats measured over 20 week experimental period. The vertical dotted line separates acclimation phase from isolation phase of study. Significance level set at $\mathrm{P}<0.05$. Note the significant increase in serum estradiol among paired groups and isolated females by 20th week compared to non-isolated control.

\section{Discussion}

Following isolation, the plasma cortisol levels in all the groups were generally higher compared to levels during acclimatization period implying that interference with social organization by capture and isolation induced stress in the naked mole rats. Similar studies showed that repeated acute stress caused an increase in cortisol, as well as reproductive hormones in Wistar rats [5]. The lower mean serum estradiol levels in female subordinate naked mole rats between day 1 to week 6 compared to the levels measured during isolation period agree with the previous studies [6] where female naked mole rats exhibited increased estradiol and progesterone levels immediately after one month of removal from their colony. There was accompanying increased steroid hormone receptors in the 
female breeders compared to non-breeding female subordinate naked mole rats. This was indicative of possible reproductive suppression that led to delayed puberty in female subordinate naked mole rats. In another similar study [7], low urinary oestrogen in the non-breeding females was reported, confirming lack of ovarian cyclicity and ovulation. The lack of ovulation in non-breeding females was ascribed to inadequate LH concentration reported earlier [8]. Results of the present study showed more significant changes in estradiol levels in both ISF and IPF by week 20, indicating a possible transformation in reproductive status of the female subordinate females. In the present study, there was no established relationship between the cortisol and the Estradiol levels. This finding is at variance with a closely related research finding done on the Sprague dowry rats [9] where it was reported that increased serum cortisol levels during exercise led to a decrease in serum progesterone which indicated possible suppression of reproduction by increased cortisol levels-a clear indicator of physiological stress. This finding is also similar to that reported in another study where levels of oestrogen and progesterone were shown to decrease as the responsiveness to stress increased [10]. In a previous study [11], it was reported that interference of pulsatile release of LH is mediated by pathways that include the synthesis of prostaglandins and cortisol. The cortisol-mediated pathway reinforced the disruption, involved mostly in suppression of cyclicity during stressful events that cause activation of the HPA axis. In the present study, other reproductive hormones (progesterone and luteinizing hormones) that could possibly vary as a result of isolation were not considered. The present study also did not consider vaginal smear instead it only focused on oestrogen levels as a marker of cyclicity.

In conclusion, reproductive suppression of subordinate female can be ascribed to the presence of the queen or other reproductive aspects that may not be directly related to stress.

\section{Acknowledgements}

We acknowledge the Kenya wildlife services for granting us permit to capture naked mole rats for research. We also acknowledge the Government of Kenya for funding our research through National Research Fund.

\section{Ethical Approval}

The research was approved by Biosafety, Animal use and Ethics committee, (REF: FAV BAUEC/2017/128) University of Nairobi and the animals were handled as directed by the committee using appropriate personal protective equipment (PPE).

\section{Author's Contributions}

A.O.M, A.W.N and R.J.M were the major contributors in writing the manuscript. H.O and A.O.M did hormonal analysis. All authors read and approved the final manuscript. 


\section{Conflicts of Interest}

The authors declare that there are no conflicts of interest.

\section{References}

[1] Abbott, D.H., Saltzman, W. and Schultz-Darken, N.J. (1998) Adaptations to Subordinate Status in Female Marmoset Monkeys. Comparative Biochemistry and Physiology Part C: Pharmacology, Toxicology and Endocrinology, 119, 261-274. https://doi.org/10.1016/S0742-8413(98)00015-2

[2] Clutton-Brock, T.H., Hodge, S.J., Flower, T.P., Spong, G.F. and Young, A.J. (2010) Adaptive Suppression of Subordinate Reproduction in Cooperative Mammals. The American Naturalist, 176, No. 5. https://doi.org/10.1086/656492

[3] Powell, R.A. and Proulx, G. (2003) Trapping and Marking Terrestrial Mammals for Research: Integrating Ethics, Performance Criteria, Techniques, and Common Sense. ILAR Journal, 44, 259-276. https://doi.org/10.1093/ilar.44.4.259

[4] Smith, M.M., Simms, C.L. and Aber, J.D. (2017) Case Study: Animal Bedding Cost and Somatic Cell Count across New England Dairy Farms: Relationship with Bedding Material, Housing Type, Herd Size, and Management System. Applied Animal Science, 33, 616-626. https://doi.org/10.15232/pas.2016-01601

[5] Olayaki, L.A. and Suleiman, S.O. (2013) Repeated Acute Restraint-Induced Stress: Effects on Body Weight Cortisol and Reproductive Hormones in Female Wister Rats. FASEB Journal, 27, 90.

[6] Swift-Gallant, A., Mo, K., Peragine, D.E., Monks, D.A. and Holmes, M.M. (2015) Removal of Reproductive Suppression Reveals Latent Sex Differences in Brain Steroid Hormone Receptors in Naked Mole-Rats, Heterocephalus glaber. Biology of Sex Differences, 6, Article No. 31. https://doi.org/10.1186/s13293-015-0050-x

[7] Hagemeyer, P., Lange, S., Broecker-Preuss, M. and Burda, H. (2009) The Influence of Olfactory Stimulus and Sexual Activity on Gonadal Steroids in Eusocial Mole-Rats. Folia Zoologica, 58, 65-74.

[8] Faulkes, C., Abbott, D. and Jarvis, J. (1990) Social Suppression of Ovarian Cyclicity in Captive and Wild Colonies of Naked Mole-Rats, Heterocephalus glaber. Journal of Reproduction Fertility, 88, 559-568. https://doi.org/10.1530/jrf.0.0880559

[9] Mosavat, M., Ooi, F.K. and Mohamed, M. (2014) Stress Hormone and Reproductive System in Response to Honey Supplementation Combined with Different Jumping Exercise Intensities in Female Rats. BioMed Research International, 2014, Article ID: 123640. https://doi.org/10.1155/2014/123640

[10] Lovick, T.A. (2012) Estrous Cycle and Stress : Influence of Progesterone on the Female Brain. Brazilian Journal of Medical and Biological Research, 45, 314-320. https://doi.org/10.1590/S0100-879X2012007500044

[11] Karsch, F.J., Battaglia, D.F., Breen, K.M., Debus, N. and Harris, T.G. (2002) Mechanisms for Ovarian Cycle Disruption by Immune/Inflammatory Stress. The International Journal on the Biology of Stress, 5, 101-112. https://doi.org/10.1080/10253890290027868 


\section{List of Abbreviations and Acronyms}

SIF-Singly Isolated Females

FIP-Females Isolated and Paired with males

NIF-Non-isolated females 